\title{
US Proposals for Free Trade in Digital Media Products: Multilateral vs. Regional Efforts
}

\author{
Heinz Hauser, Sacha Wunsch-Vincent \\ Universität St. Gallen, SIAW, Dufourstr. 48, 9000 St. Gallen, Switzerland \\ Institute for International Economics, Washington D.C., 20036, USA
}

\section{Introduction}

Professor Beat Schmid has pioneered ideas which are of crucial importance for this article: When information technology was still seen by most academics and business men as a technical revolution which allows rapid and large scale transmission of information, he already formulated very convincingly the fundamental change this new technology would have on business models and market architecture. He foresaw very clearly that the convergence of technologies (communication, TV, media for movies and music) would have profound effects on existing market structures and industry delimitation. The fact that it has become difficult to define economic transactions either as good or as service - a long debate in the WTO with far-reaching implications for the regulatory environment - will not come as a surprise to him. Research at the Institute for Media and Communications Management, which Professor Beat Schmid leads as Managing Director from its inception, has always included projects on market structure and regulatory regimes for the ,new electronic world“. He was convinced that the information technology ,revolution" would bring major challenges for management science and practice, as well as for the legal and economic disciplines. His call was for research and discussion that transcends traditional disciplinary demarcations.

One field which fits perfectly into his research interests is the growing importance of digitally traded media products (to avoid the classification issue goods vs. services) on a global scale. Because the U.S media industry has a clear competitive advantage, pressures on the U.S. government are mounting to negotiate an open free trade regulatory regime for digital media products. This meets resistance on the part of (mostly but not exclusively European) countries who underline the "diversité culturelle" and the 
need for policy flexibility with regard to trade in products that have a (real or alleged) strong impact on culture. The U.S reacted by including their digital trade agenda in recent efforts to conclude bilateral or regional Free Trade Agreements (U.S. - Chile and U.S. - Singapore being the first ones). The international regulatory framework for digital media products will be shaped by the strong political demand in the U.S. for an open trade framework and by their concurrent parallel negotiations on the bilateral, regional and multilateral level - the theme of the following discussion.

\section{The Rise of Cross-Border Trade in Digital Media Products}

The starting point of this analysis is the growing international trade of digital products ${ }^{1}$ like movies, software, entertainment games and music that can be conducted electronically and therefore independent from physical media carrier (e.g. VHS tape, CD).

Admittedly, trade of online content is still plagued by low bandwidth that complicates the downloading of large files (e.g. movies). Furthermore, copyright piracy has slowed the legitimate online trade of digital products. Since the closure of Napster an even broader range of high-quality filesharing communities (e.g. Kazaa Lite) has arisen that - in violation of the artists' intellectual property rights (IPRs) - makes movies or music available for free. The fact that the digital product industries are therefore hesitant to make their content available for sale online, but also the lack of visionary business models for such an online environment, have caused a lack of viable commercial efforts to exploit the digital trade potential.

However, every day technological evolutions and improved business models provide new impetus to these digital trade flows. Technologies increasingly converge and contents themselves thus become much more „portable“ throughout different technologies. In that process, the boundaries between software, telecommunication or audio-visual services (e.g. multimedia online game) get blurred and even the difference between what

1 The term digital products refers to computer programs, text, video, images, sound recordings and other products that are digitally encoded, regardless of whether they are fixed on a carrier medium or transmitted electronically. With the term "product" the authors refer to both goods and services. Moreover, the definition only covers point-to-point transactions that entail electronic transmission using any electromagnetic or photonic means. 
is considered a good or a service becomes uncertain ${ }^{2}$. New streaming and copy-protection technologies, faster network connections (e.g. DSL), more portable hardware to store and access downloaded content (e.g. Archos Jukebox), the increasing convergence between television and the Internet, the rise of online entertainment games, the spread of cable TV with its many outlets for Pay-per-View, etc., have improved the feasibility of trade with digital products. One also observes a learning curve of the copyright industries in terms of business models that actually try to embrace the new technologies' potential. A significant amount of business-to-business trade in software is already conducted over electronic networks. But things are also moving with respect to the online distribution of music and movies. The recent debut of the Apple's iTunes Music Store is already hailed as a new era for how the music business will be conducted over the global medium $^{3}$.

In sum - although hard to measure directly -international trade of digital products will be one of the most fascinating and fastest-growing trade flows to be seen in the near future ${ }^{4}$. As U.S. companies dominate the entertainment and software industry it is not surprising that U.S. Congress has instructed its trade negotiators last year to vigorously pursue a new digital trade agenda in which the most trade-friendly treatment is accorded to digital products 5 .

\section{Ambitious Objectives of the U.S. Digital Trade Agenda}

As has been demonstrated above, electronic trade of digital products must overcome many technological barriers and piracy problems to flourish. But as opposed to many other tradable goods and services that have to overcome tariffs or discriminatory regulations, the online trade of digital products does not yet face trade barriers erected by governments that discriminate between content suppliers of different origin. In practice that means that so far no tariffs on digital transactions are applied. And although dis-

2 If, for example, software is sold online over proprietary networks and without being burnt on a CD-Rom, the question arises if a service or a good has been exchanged.

3 See http://www.apple.com/music/store/.

4 See part 1.3.2 of Hauser and Wunsch (2002) for the measurement problems and the current trade figures for digitizeable media content. See Mattoo and Schuknecht (2001) for an estimation of the trade potential.

5 This mandate is part of the new fast-track negotiation authority concluded in 2002. 
criminatory local content quotas or other audio-visual measures are widespread in the offline world (i.e. broadcasting and cinema quotas), no government is known to have enacted similar trade barriers applicable to electronic transmissions. At this stage digital products are exempt from most regulatory frameworks (except IPR protection).

This free trade environment - so uncommon in other product areas - may however change anytime. This holds true because the phenomenon of digital products somehow evades the current rules and standing obligations of the World Trade Organization (WTO). Consequently, the US digital product industries and the United States Trade Representative (USTR) demand that ongoing and future trade negotiations should be used to lock in free trade for digital products. Trade rules are part of a wider digital agenda of the US which is not developed systematically at this point ${ }^{6}$. This text concentrates on market access issues for electronically delivered digital products. These contain the following four core provisions:

1. Ensure that current obligations, rules, disciplines, and commitments under the WTO apply to digital trade.

2. Ensure that electronically delivered goods and services receive no less favourable treatment under trade rules and commitments than like products delivered in physical form. Ensure that the classification of such goods and services protects the most liberal trade treatment possible ${ }^{7}$.

3. Extend the WTO duty-free moratorium on electronic transmissions.

4. Ensure that, when possible, the most liberal form to schedule trade commitments (negative list approach) is used so that new services are automatically covered by old commitments, and ensure the absence of discrimination against electronic service delivery.

To increase the level of free trade commitments, the US asks the WTO Members to adhere to the Information Technology Agreement (ITA) that mandates the elimination of tariffs on physical media carriers that carry content. In case tariffs are levied, the U.S. asks its trading partners to levy the customs duties on the value of the media carrier rather than on the value of the generally more expensive content itself.

6 The other aspects of the US digital trade agenda are discussed in WunschVincent (2003).

${ }^{7}$ Given that for movies and other digital products commitments in the GATT are almost always greater than commitments in the GATS, the most liberal trade approach to the classification questions is a more elegant way of asking not to submit digital products to the market access and national treatment limitations entered for audio-visual services. 
Moreover, the US believes it is important to increase free trade in the three service categories most relevant to electronic digital trade. Regarding audio-visual services, the U.S. strategy has evolved from asking for an elimination of all discriminatory market access barriers to requests that U.S. trade partners should "freeze" their current level of discriminatory audio-visual regulations in their GATS schedule. With this negotiation objective, the USTR is making sure that new means to trade digital products are covered by free trade principles. With respect to telecommunication and computer and related services, the US asks its trade partners to deepen and broaden commitments for value-added telecommunications and for computer and related services. When U.S. negotiators stress that "all" software services should be covered by computer service commitments, this is an indirect appeal to resist any temptation to extend audio-visual exemptions to software that contains music or video sequences (i.e. entertainment games).

Most of the elements of the U.S. digital trade agenda can only be understood in the context of questions that were actually first raised on the multilateral level in 1999 by the "WTO Work Program on E-commerce". The open WTO e-commerce questions are (i) whether the duty-free moratorium on all digital transactions that has been temporarily agreed on in the WTO in 1998 should be made permanent and (ii) which rules and commitments should apply to digitally delivered content. Concerning the latter, uncertainty arose on whether products delivered in digital form should be treated as goods (GATT-like treatment ${ }^{9}$ ) or as services (GATS-like treat$\left.m e n t^{10}\right)$. As content was traditionally imported on physical carrier media it was hitherto considered under the GATT. But now that bites and bites travel across borders without a physical medium some WTO Members claim that digital product transactions should be classified as services and hence be captured by the GATS. Even if considered under the GATS, WTO Members must also agree under what GATS commitments in the different categories of "value-added telecommunication", "audio-visual services" or "computer and related services" digital content falls.

These classification issues and the decision on the moratorium on electronic transactions have a very tangible effect on the applicable degree of trade liberalisation. Whereas in the multilateral trading system physical carrier media under the GATT are subject to only few or - if the WTO

${ }^{8}$ See Wunsch-Vincent (2002) for a more detailed discussion of these questions.

9 GATT stands for General Agreement on Tariffs and Trade. This is the WTO Agreement that aims to establish free trade in goods.

${ }^{10}$ GATS stands for General Agreement on Trade in Services. This is the WTO Agreement that aims to establish free trade in services. 
Member is a signatory to the Information Technology Agreement - no customs duties or import quotas, the same content can face severe market access barriers or even absent trade commitments altogether when classified under certain GATS service classifications. This holds true as for example the GATT mandates national treatment and forbids any quotas, whereas, depending on the level of commitments, derogation from the national treatment principle and quotas can be compatible with the GATS ${ }^{11}$. The much weaker trade obligations of the GATS become particularly apparent depending in which of the three above-mentioned service category one classifies digital products. Whereas for computer services almost half of the WTO Members have committed to free trade, only few Members have made commitments to audio-visual services.

\section{Obstacles to the U.S. Digital Trade Agenda on the Multilateral Level}

Despite U.S. efforts that led to the WTO E-commerce Work Program in 1998, none of the above-mentioned U.S. digital trade objectives has been achieved on the multilateral level. The logjam in the WTO E-commerce Work Program is well reflected in the Doha mandate's paragraph on ecommerce that only instructs the General Council to rethink institutional arrangements until September $2003^{12}$. Currently, not even a formal agreement exists that the WTO rules and obligations apply to e-commerce ${ }^{13}$. The WTO duty-free moratorium on e-commerce agreed on in 1998 expires if no action is taken during the Cancun Ministerial ${ }^{14}$. Furthermore, there are still unanswered questions essential to legal certainty and digital market access concerning the classification of electronic services and digital products.

${ }^{11}$ See for other differences between the GATT and the GATS that are relevant to e-commerce Hauser and Wunsch (2002), p. $74 \mathrm{ff}$.

${ }^{12}$ See para. 34 of the Doha Mandate: "[...] We instruct the General Council to consider the most appropriate institutional arrangements for handling the Work Programme, and to report on further progress to the Fifth Session of the Ministerial Conference $[\ldots]$ '.

${ }^{13}$ Some members actually question whether, for example, GATS mode 1 commitments on cross-border trade actually apply to electronic transactions.

${ }^{14}$ See para. 34 of the Doha Mandate: "[...] We declare that members will maintain their current practice of not imposing customs duties on electronic transmissions until the Fifth Session [...]". 
The reasons for this lack of a classification decision with respect to digital products is mostly political: WTO Members like the EC and Canada maintain that digital products should be classified as services and see the U.S. proposals to afford GATT treatment to digital products as an attempt to circumvent the cultural exemption. Although not addressed directly by the EC, the classification under the GATS would in turn allow the WTO Members to extend their practice of discriminatory limitations and cultural support measures to audiovisual services delivered online. The U.S. on its side wants to avoid the spread of cultural exemptions to the online trade of content.

On the goods side, the U.S. is likely to be able to use the current Doha negotiations to request accession to the Information Technology Agreement (ITA) from non-members ${ }^{15}$. As the ITA currently encompasses only 59 out of 146 WTO Members, scope for improvement exists. Nevertheless, given the debate on the cultural exemption it is highly unlikely that WTO Members can agree on a formal decision to base customs duties on the value of the carrier media rather than on the content. On the services side, the GATS request and offer process (initial requests were due in July 2002 and initial offers in March 2003) provides the platform to deal with the specific market access commitments for the three relevant service areas. Generally, the low level of commitments of many developing countries and their seemingly greater interest in obtaining market access to other service markets indicate that improvements with respect to cross-border GATS commitments in the fields of computer and telecom services and in other service sectors are to be expected. However, the situation for negotiations on audio-visual services - the field with the greatest relevance to digital products - is less clear. On the one hand, the technological evolutions, the new interest of developing countries in market access for digital products (India, Brazil, etc.), the notion that trade rules may be sufficiently flexible to address all aspects of the audio-visual sector, and the sustained interest of the U.S. have certainly introduced new components to the debate. All in all, the likelihood that an open transatlantic confrontation will paralyse the audio-visual service negotiations from the beginning is reduced.

On the other hand, the resistance of many WTO Members to schedule market access commitments will be fierce. Especially the countries with greatest markets for digital products like the EC, Canada and Australia have made it very clear that no offers will be made for the cultural service sectors and that no classification of digital products under the GATT will

\footnotetext{
${ }^{15}$ See "U.S. E-Commerce Industry Plots Strategy for WTO Talks", Inside U.S.
} Trade, May 24, 2002. 
be accepted. Under the new header of "diversité culturelle", especially France, Canada and other WTO Members are currently trying to push the issue of audio-visual service liberalisation outside the WTO (mostly to the UNESCO). Recent EC proposals to exclude any software or computer services with audio-visual content from the very liberal commitments on computer services would even extend this approach. ${ }^{16}$ Content itself and any multimedia products like entertainment games would then be marginalised in the GATS audio-visual sector category where commitments are mostly absent.

In sum, it is very unlikely that a classification decision for digital products is taken in the near future. In the WTO the US may well focus only on obtaining another temporary duty-free moratorium on electronic transactions and a positive statement from the WTO about the importance of freetrade principles and rules to the development of global e-commerce. Furthermore, it looks as if some of the biggest markets for digital products (except the US) will opt to interpret the questions of classification in the least-trade liberalising way.

\section{First Successes on the Bilateral Front and More to Come...}

The implementation of the U.S. trade agenda with respect to securing market access for digital products looks quite different if one considers the two first preferential trade agreements concluded among the flurry of planned U.S.-driven bilateral and regional Free Trade Agreements (FTAs). Unimpressed by the deadlock or the slow progress on digital trade matters in the WTO, the U.S.-Chile and the U.S.-Singapore Free Trade Agreements set groundbreaking precedents for future U.S. and other digital trade objectives in trade agreements. ${ }^{17}$

As both Chile and Singapore are Members of the ITA this digital trade objective of the U.S. was satisfied from the start. Singapore agreed that for

${ }^{16}$ See "Consultation on the GATS 2000 / WTO negotiations concerning certain audiovisual services and cultural services", Internet: http://europa.eu.int/ comm/avpolicy/extern/gats2000/ncon_en.htm where internally the EC questions whether entertainment games should be subject to a cultural exemption. See also WTO document S/CSS/W/34/Add.1, July 15, 2002. In this proposal the EC tries to make sure that only IT services but no content services get coverage through computer service commitments.

${ }^{17}$ USTR (2003a, 2003b), from Gobierno DE CHILE (2003) and personal discussions with the USTR. 
digital products delivered on physical carrier media customs duties would be assessed on the value of the carrier medium only. When it comes to trade in services, both U.S.-Chile and U.S.-Singapore follow the U.S. negotiation objectives and use the most liberal form to schedule trade commitments (the negative list approach). Basically, the most-favoured nation approach (MFN), market access, and national treatment must be granted to all services provided on a cross-border basis if limitations to these principles are not specifically scheduled. This top-down approach guarantees that narrow classification schemes (i.e. the classification of entertainment games under audio-visual vs. computer services) do not limit the applicability of commitments to digital products or electronic services ${ }^{18}$ and those new services are automatically covered by past commitments. The parties to the two agreements thus have accorded significant market access across their entire service regime, and have listed only very few limitations. Especially, the cross-border trade in computer and in telecommunication services is well-covered by these commitments.

When it comes to audio-visual services, both Chile and Singapore have accepted to dismiss the notion of a fully-fledged "exception culturelle". Both have agreed to make specific commitments on their audio-visual service sector while retaining room of manoeuvre in order to maintain central elements of existing and, in some cases like subsidies, future cultural policies (see Gobierno de Chile 2003). Instead of maintaining full policy flexibility with respect to audio-visual services, the two U.S. trade partners both agreed to schedule and thereby freeze their existing discriminatory regulations applicable to audio-visual services. Chile, for instance, has only listed a few limitations: a ceiling to its national broadcast quota at $40 \%$, some nationality requirements for important positions in the Chilean media industry, limitations on radio licenses when the invested foreign capital exceeds a certain percentage, etc (see Gobierno de Chile 2003). As no discriminatory regulations currently exist for new media, the Chileans thus agreed to full market access and national treatment obligations for all audio-visual services transmitted by these new electronic delivery modes (including cable or satellite transmission). At the same time, the Chileans scheduled limitations that guarantee that any current or future financial support scheme for Chilean culture can be maintained.

The greatest innovation of the two new bilateral FTAs of the U.S. is, however, their inclusion of legally binding and very similar e-commerce chapters. Both agreements recognise that e-commerce is an important means of trade and that new trade barriers to digital trade - including e-

\footnotetext{
${ }^{18}$ In fact, then no separate categorisation baskets exist any longer for a set of products that is converging anyway.
} 
commerce regulations that are more burdensome than necessary - should be avoided. Specifically, the parties agree to a permanent duty-free moratorium for electronic transmissions of digital products ${ }^{19}$.

The first e-commerce chapters ever to be legally integrated into a trade agreement actually address the issue of digital products as a discipline separate from the issue of trade in goods or services ${ }^{20}$. Without actually taking that politically contentious classification decision, the e-commerce chapters create special trade disciplines for digital products that guarantee national treatment on the basis of MFN (and therefore non-discrimination) to a comprehensive set of digital products (video, any kind of software, etc). Although in the U.S.-Chile agreement the contracting parties have one year to list existing non-conforming measures to these obligations, outside of these limitations the principle of non-discrimination applies to all digital products delivered electronically.

Interestingly, the electronically delivered digital products need not be fully created and exported via one of the contracting parties to benefit from these principles. The e-commerce chapters indicate that they must only transit through or be created, altered, published on the territory of either contracting party, or be created by a citizen of either contracting party to benefit from this most trade liberal treatment. In effect, this means that digital products from other countries can benefit from the obligations under the bilateral U.S.-Chile FTA if their products are, for example, routed over or transformed in Chile before they are sent to the U.S. (see Gobierno de Chile 2003) Moreover, the rules and obligations on e-commerce apply horizontally without introducing a distinction between goods and services. Finally, the U.S. has elaborated a non-binding "Joint Statement On Electronic Commerce" with certain regulatory principles.

Now that the U.S. industry's expectations are high, the U.S. agreements on digital trade with Singapore and Chile are just the start when it comes to the U.S. digital trade ambitions. What the U.S. has not yet achieved on digital trade multilaterally, it now plans to seed in a tight net of gradually increasing bilateral agreements that are negotiated in a parallel or sequential fashion and that pursue these high benchmarks. The pending bilateral trade negotiations with Australia, Morocco, SACU, CAFTA, and more new bilateral FTA partners to come will be used by the US to drive their

${ }^{19}$ This obligation does not preclude any party from imposing GATT consistent internal taxes or other internal charges. See Art 14.3 of the U.S.-Singapore Agreement and Art. 15.3 of the U.S.-Chile Agreement.

${ }^{20}$ See Art. 14.3 of the U.S.-Singapore Agreement and Art. 15.4 of the U.S.-Chile Agreement. 
liberalization blueprint. ${ }^{21}$ On top of the geographically dispersed bilateral agreements that target Asia, Africa and countries in South America, the negotiations to conclude the Free Trade Agreement of the Americas (FTAA) in 2005 are also progressing on the regional front. ${ }^{22}$ Accordingly, the readiness of potential FTA partners to include aspects crucial to U.S. interests on digital products will now be a key criteria in the selection of further U.S. bilateral FTA partners.

\section{Global Consensus via Preferential Trade Agreements?}

Currently, the WTO Members are not ready to update the multilateral trade system in the way the U.S. believes is necessary to have a modern trade framework for the digital economy. At the same time the U.S. has had its first successes in creating a web of preferential trade agreements that corresponds more fully to the American industry's expectations. In the preferential trade negotiations to come, the U.S. will continue to drive its "model approach" to digital trade.

This parallel track of multi-level negotiations is a rather new phenomenon for the U.S. Consequently, the question of the malign or benign relationship between the preferential and multilateral trade treaties arises. Furthermore, one must wonder how probable it is that the new U.S. strategy that follows a bottom-up approach (from bilateral to higher levels) will be successful. The authors would like to conclude by addressing these two questions.

Concerning the first question of whether the bilateral U.S. digital trade agreements are a "building or a stumbling block" to the WTO, it is fairly safe to subscribe to the building block hypothesis. The pursuit of the U.S. digital trade agenda in preferential trade deals is part of a concurrent strategy that envisages as its final goal the establishment of free digital trade on the global level. To stop short at the conclusion of a few bilateral FTAs is not the intention of the U.S. for two reasons. First, the U.S. knows that a scattered set of bilateral agreements is not satisfactory to do justice to trade conducted via global electronic media. It is also simply impossible to ne-

\footnotetext{
${ }^{21}$ The South African Customs Union (SACU) encompasses South Africa, Botswana, Namibia, Lesotho and Swaziland. The U.S.-Central American Free Trade Agreement (CAFTA) will be negotiated with Costa Rica, El Salvador, Guatemala, Honduras and Nicaragua.

${ }^{22}$ The FTAA is under negotiation between all 34 countries of the Western hemisphere except Cuba.
} 
gotiate heterogeneous trade agreements on the treatment of digital products with 146 WTO Members. Second, both the U.S. industry and the U.S. negotiators know that especially with respect to digital trade flows Chile, Singapore, SACU, etc. are still fairly unimportant economies. The greatest digital trade flows are obviously with trade partners like the EC and Japan that the U.S. is unlikely to sign FTAs within the near future.

All these arguments reinforce the impression that the U.S. perceives these bilateral agreements as a building bloc to subsequent negotiations and that it regards their strategic value as high initial benchmarks. ${ }^{23}$ Seen from this perspective an unprecedented phenomenon of a more direct causal interdependence between bilateral FTAs and regional or multilateral negotiations comes into play, which the USTR has recently called a strategy of „competitive liberalisation“. Under this principle, the U.S. intends to negotiate preferential trade agreements in parallel to the WTO negotiations to avoid being slowed down in its trade objectives by the growing difficulty to make decisions in the WTO forum and because it believes that these bilateral or regional trade deals can actually increase the pressure on other WTO Members to come forward with satisfactory offers on the multilateral level.

Concerning the second question of how probable it is that the new U.S. strategy will be successful, the assessment is less clear-cut: To begin with, it is very likely that in the next bilateral negotiations with Morocco and SACU, for example, the U.S. may successfully use its much greater bargaining power to continue achieving its digital product objectives. With respect to traditional topics like the free trade in IT goods and more service liberalisation in fields like computer services, the bilateral U.S. strategy will produce much more trade openness from developing countries. The strategy will certainly also succeed in fostering a common approach to digital products.

But it is highly uncertain whether the U.S. bottom-up approach will work all the way through for the treatment of digital products. Very soon the U.S. will start to feel the limits of their concurrent negotiation approach and their attempt to build large like-minded coalitions. When the U.S. starts approaching partners for preferential trade agreements that are economically important and that are also very inclined to rank "cultural diversity" high on their agenda, the U.S. negotiators will face the same problems as in the WTO. In particular, the FTA with Australia and the negotiations with Canada in the context of the FTAA will force the U.S. to reconsider their liberalisation blueprint as both countries are unlikely to

${ }^{23}$ See "USTR Defends Choice Of Free-Trade Agreement - Partners Against Critics", Inside U.S. Trade, January 10, 2003. 
make concessions on cultural services or to sign up to a discipline concerning digital products that is anywhere close to the blueprint proposed in the FTAs.

If one thinks one step ahead and tries to test the viability of the U.S. approach for the WTO, the same reservations apply. The idea of formulating a trade discipline for digital products that is detached from the standing WTO agreements and is situated between the GATT and the GATS will not be acceptable to the majority of WTO Members. Rightly so, as the US template creates more questions than it actually answers. One the one side, one must acknowledge that the U.S. approach is the best way to secure unconditional and comprehensive full market access and national treatment for current and future digital products without really deciding whether they are goods or services. As the US approach avoids the GATT vs. GATS decision it is unclear whether the trade disciplines from the goods or the services agreements still apply to digital products. The cost of creating a digital product discipline that is otherwise in a legal vacuum is quite high and - according to all WTO members which have already accepted the EC position (Hong-Kong, Brazil, Thailand, Switzerland, Norway) - not feasible on the WTO level. Another problem is that an overlap between these disciplines and standing specific commitments either under the ITA or under existing GATS commitments would be created. Overlaps or the need to revisit standing obligations is something that most WTO Members (and especially the U.S.) avoid to do out of fear that some Members will use the opportunity to dilute existing commitments or that a Pandora's box of conceptual new questions arises that will be difficult to close again. The U.S. negotiators are well-aware of the dilemma. In fact, they have - so far - no intention to propose the regional blueprint on the WTO level. Therefore, the practical value of the U.S. liberalisation blueprint in terms of adopting this same approach at the WTO is of not much value.

Nevertheless, the regional U.S. moves have certainly injected a healthy new dynamism to the debate. As more and more countries will be approached bilaterally or in regional trade agreements to secure free trade for digital products they will also tend to be more flexible to come up with a proper compromise at the WTO level. When its support base is big enough, the U.S. will eventually at some point in time try to propose a WTO agreement that individual Members are free to join (e.g. Reference Paper).

Without such efforts on the WTO level, the opportunity to lock in free trade for digital products will slip away and it will be more difficult to eradicate trade barriers ex post that have arisen. This situation would be more than unfortunate as the use of technology to conduct digital trade would actually be discouraged. Worse of all, nascent trade flows and the 
business models that go with it would be choked off before they even develop.

\section{References}

Gobierno de Chile (2003) Tratado De Libre Comercio Chile-Estados Unidos - De Qué Se Trata?. Dirección General de Relacciones Económicas Internacionales Prochile, January 16, 2003, Internet: http://www.direcon.cl/frame/tlc/ f_espanol.html (downloaded February 25, 2003)

Hauser, Heinz, Sacha Wunsch-Vincent (2002) The Cross-Border Trade in Electronic Services: The Role of the WTO and Challenges to National Policies. Expert Report for the German Parliament (Büro für TechnikfolgenAbschätzung beim Deutschen Bundestag), April 2002, available in German, Internet:

http://www.siaw.unisg.ch/org/siaw/web.nsf/SysWebRessources/h01hbund/\$FI LE/gutbund.pdf (downloaded February 20, 2003)

Mattoo, Aaditya, Ludger Schuknecht (2001), A WTO-Framework for the New Economy. paper presented at the Paderborn Konferenz on "Economic Policy in the New Economy", May 15-16, 2001, mimeo.

USTR (2003a) Free Trade With Singapore - America's First Free Trade Agreement in Asia. Trade Facts Sheet, January 2003, Internet: http://www.ustr.gov/ regions/asia-pacific/2002-12-13-singapore_facts.pdf (downloaded February 20, 2003)

USTR (2003b) Free Trade With Chile - Significant New U.S. Access to South America's Most Dynamic Economy. Trade Facts Sheet, January 2003, Internet: http://www.ustr.gov/regions/whemisphere/samerica/2002-12-11-chile_ summary.pdf (downloaded February 20, 2003)

Wunsch-Vincent, Sacha (2002) Outstanding WTO Issues and Deliverables with Respect to the Electronic Cross-border Trade of Digital Products. Chapter 2 of $\mathrm{PhD}$ thesis' draft, Internet: http://www.cid.harvard.edu/cidtrade/Papers/ Wunsch_WTO.pdf (downloaded February 20, 2003)

Wunsch-Vincent, Sacha (2003) The Digital Trade Agenda of the U.S.: Parallel Tracks of Bilateral, Regional and Multilateral Liberalisation. Aussenwirtschaft; March 2003, Internet: http://www.iie.com/publications/papers/ wunsch0303.pdf (downloaded May 30, 2003) 